\title{
Robust Science: Passive Smoking and Scientific Collaboration with the Tobacco Industry in the 1970s
}

\author{
Uri Shwed
}

Ben Gurion University of the Negev

Abstract: The first lesson from the history of research on smoking hazards is that scientists should be wary of collaboration with interested industries. This lesson, which is influential in the literature on science-industry relationships, comes from a historiography focused on the carcinogenicity debate of the 1950s and 1960s and the passive smoking debate of the 1980s and 1990s. Few studies have examined research in the 1970s. This article fills this lacuna using novel bibliometrical methods augmented with a qualitative analysis of the associations between periods and literary camps, as expressed in scientific texts. The mixed-methods approach identifies the temporal dynamics of the literature on smoking hazards to reveal that the well-documented attempts of the tobacco industry to stall and hamper science had unanticipated consequences. Specifically, an industry-science collaboration to develop a less hazardous cigarette put scholars on the path to discovering the hazards of passive smoking. The analyses supply a narrative that has room for actors' complex interests and actions and demonstrates that such complexity may only be revealed in research whose outcomes are never known in advance.

Keywords: sociology of science; social network analysis; tobacco; historical sociology; environmental tobacco smoke; mixed methods

Citation: Shwed, Uri. 2015. "Robust Science: Passive Smoking and Scientific Collaboration with the Tobacco Industry in the 1970s." Sociological Science 2: 158-185.

Received: August 17, 2014

Accepted: November 2, 2014

Published: April 1, 2015

Editor(s): Jesper Sørensen, Delia Baldassarri

DOI: $10.15195 / \mathrm{v} 2$. a9

Copyright: (C) 2015 The Author(s). This open-access article has been published under a Creative Commons Attribution License, which allows unrestricted use, distribution and reproduction, in any form, as long as the original author and source have been credited. (0)(1)
THE science of smoking hazards has become an iconic cautionary tale about the interface of science and industry (Markowitz and Rosner 2003; Michaels 2008; Oreskes and Conway 2010). It represents one case in which the "funding effect" (Krimsky 2006) — the ability to hamper research results through funding—is explicitly demonstrated (Barnes and Bero 1998). It is thus constructed as a model that warns scholars about collaborating with industries (Proctor and Schiebinger 2008). Its importance as an iconic cautionary tale positions the case as a strategic research site (Merton 1987) for science-industry relations. Many critiques of science-industry relations start with a reference to the tobacco industry (Proctor and Schiebinger 2008; Oreskes and Conway 2010; Abraham and Ballinger 2012; Smith 2013) and its history of preventing science from promoting health and knowledge. It is therefore a good case for a contemporary sociology of science that seeks to expose the politics within science.

The magnitude of science-industry collaboration, however, makes pure science ideals anachronistic at the very least (Lam 2010; Shapin 2008). Serious engagements with this issue infrequently call for the need to purify science from industry (Brown 2000) and more frequently call for the management of the inherent conflict (Resnick 2007). Sociologists suggest that such collaborations generate a new knowledge production regime (Vallas and Kleinman 2007), with some separation between 
commercial and academic logics maintained by hybrids (Murray 2010; see also Lam 2010). Evans (2010) and Mody (2006) suggest that industries' less theoretically committed approach may push scientists toward unexpected discoveries. This article joins this effort and extends Evans's suggestion: industry's effect on science may push scientists in new directions.

This "extension" is unique in that it does not rest in an esoteric 21st-century subfield of an exciting new technology but in the very essence of the iconic 20thcentury science-industry conflict between epidemiology and the tobacco industry. By collaborating with prominent scientists, the tobacco industry not only stalled knowledge production and its dissemination (see, e.g., Barnes and Bero 1998) but also facilitated its advancement in unanticipated directions that led to the scientific triumph in the so-called tobacco wars. A rarely discussed yet notorious episode in this history is a collaboration known as the Tobacco Working Group (TWG). The TWG attempted to develop a less hazardous cigarette and had, I argue, a crucial, unintended effect on the science of smoking hazards. Specifically, whereas others see the TWG as another industry stalling maneuver (Parascandola 2005a), I show that it was a necessary step that provided the "conditions of possibility" (Foucault 1973) for passive smoking research, which became a banner for the antitobacco movement (Bayer and Colgrove 2002). Previous engagements that were focused on specific periods failed to see this association, but an overview of the entire scientific dynamic of the case reveals it.

Accounts of the science of tobacco hazards have successfully anchored the scientific debates concerning carcinogenicity (e.g., Proctor and Schiebinger 2008; Ong and Glantz 2001), passive smoking (e.g., Ong and Glantz 2000; Barnes and Bero 1998; see also Kabat 2008), and, recently, harm reduction (e.g., Parascandola 2005b; Fairchild and Colgrove 2004) in their societal and political contexts. Such studies have provided ample evidence for the industry's attempts at concealing knowledge, disturbing scientific research, and manipulating the public and authorities on various issues (Michaels 2008; Oreskes and Conway 2010). None of these studies provided a complete narrative of the scientific progress of the literature on smoking hazards. None told a story that tracks the scientific evolution of the case from one research topic or debate to the next. Almost all engagements with this literature were focused on the pre-1964 carcinogenicity debate (does smoking cause cancer?) or on the post-1981 passive smoking debate (does cigarette smoke cause cancer among nonsmokers?). The few works that focused on the interim period between these debates did so with a substantive historical interest in harm reduction or in the science-industry relationship of the harm reduction project without attempting to weave these three periods together. Canonical historiographies (e.g., Kluger 1996; Brandt 2007) of the case did provide a comprehensive narrative, but as far as science was concerned, they shared a disconnect between the carcinogenicity and the passive smoking debates, with nothing to very little discussed in between. The current article reveals a new, general lesson from this case by attempting to connect these hitherto disparate dots.

This attempt was made possible by a novel methodology that can process entire bodies of literature as citation networks and evaluate their internal dynamics (Navon and Shwed 2012). The method uses a network analysis algorithm to apply 
actor-network theoretical (ANT) notions of citation and literature dynamics, particularly the notion of fact construction as black boxing (see Shwed and Bearman 2010; Latour 1999). It joins Asdal's (2012) call for ANT application as a historicizing method. Without such a methodology, there is no reason to doubt the well-founded canonical historiographies of the case, which say little about the 1970s. However, arming the analysis with a quantitative method suggests that the relative absence of secondary writing on the 1970s is itself an important issue. Thus the analysis here both focuses the question-what happened in the smoking hazards research literature of the 1970s? - and provides an answer. Augmented with the content analysis of scientific articles and secondary sources, the rigid quantitative analysis turns into a narrative of the entire history of the smoking hazards literature, not only its most contentious moments.

The analysis considers science demarcated from other social activities and focuses on scientists and their products. This methodological decision cuts through entrenched oppositions by respecting both quantitative analyses of the traces of science and the thick stories surrounding it. It is also a countermeasure to existing accounts that are saturated with context at the expense of scientific substance. In fact, the limitations of previous accounts may be limitations of a purely qualitative approach; it is very difficult to encompass a single account of such a long history without some quantitative heuristics. The available qualitative heuristics are exactly those that shun the canonical reports away from 1970s science, in this case. Employing strict analytical procedures that focus on the content of science, this article shows that despite well-documented industry malfeasance, scientists may cultivate industry resources for research whose outcomes are never known in advance. In this sense, science may be robust. Of course, this unintended robustness of "pure science" exactly where it is most soiled by the industry bears significance for every consideration of science-industry collaboration.

The next section provides a concise introduction to the canonical writing on this case. The third section outlines how a quantitative historical analysis revealed the empirical puzzle of this case-what happened in this literature in the 1970s—and provided an alternative interpretation based on an analysis of citation networks. The fourth section augments the conclusions of the quantitative analyses with a qualitative analysis of approximately 250 research articles (of the 8,874 articles analyzed quantitatively) to offer a coherent narrative of the tobacco studies field. In conclusion, I offer implications for industry and science collaborations and, more broadly, for sociological research.

\section{Brief Historiography of Tobacco Studies}

Previous accounts of the history of the association of smoking and cancer have successfully anchored scientific debates in their societal and political contexts (e.g., Brandt 2007; Kluger 1996; Proctor 1995). In such accounts, scientific activity was scrutinized inasmuch as it was engulfed in contestation with the industry, primarily in the 1950s debate on the hazards of smoking and the 1980s debate on the hazards of passive smoking. 
The scientific claim that smoking is a health hazard began in the late 1940s, led in the United Kingdom by Richard Doll and in the United States by Evarts A. Graham (who was to die of lung cancer a decade later) and his student Ernst Wynder. Both teams found associations between smoking and lung cancer (Mukherjee 2010). A methodological debate ensued, and the tobacco industry sponsored many of the objections (see, e.g., Brandt 2007:143, 68-89).

Viewed from the present, the objections to the carcinogenicity claim are dismissed for social and political reasons. Some are dismissed for sociopsychological reasons given by the people involved, primarily smokers themselves; "quitting was harder than the evidence for it" (Davis 2007:142). Others portray these objections as a prestige dispute between scientists who espoused different methodologies (Kluger 1996; Kabat 2008). Some describe such challenges as a blatant industry manipulation of science (Brandt 2007:159). This last argument is made, to some degree, in all of the earlier ones; challenges to the claim of tobacco's carcinogenicity are always viewed as promoted and fueled, if not produced wholesale, by the tobacco industry.

Yet, despite the immense power of the tobacco industry, each objection generated an adequate scientific response. Methodology was sharpened; control-case matches and age-adjusted hazard ratios replaced simple associations. Animal models were used to generate cancer in mice. Gradually, it became clear that virtually all independent scholars in the field agreed with the carcinogenicity claim, whereas a small, industry-sponsored minority objected (Brandt 2007). In 1964, the U.S. Surgeon General published the famous "Report on the Hazards of Smoking," which addressed every methodological objection and determined that smoking causes cancer.

A similar story of an industry-sponsored faux scientific debate is told about the 1980s, this time debating the hazards of passive smoking. In 1981, two articles argued that there was evidence of health hazards from tobacco smoke among nonsmokers (Hirayama 1981; Trichopoulos et al. 1981). These papers generated a fierce methodological debate about what constitutes proof and how exposure to environmental tobacco smoke (ETS) may be measured. Three decisive reports by the Surgeon General, the National Science Foundation, and the International Agency for Research on Cancer silenced the debate in 1986. Some continued to argue that these reports were political and that the proof was weak. A final report of the Environmental Protection Agency in 1992 silenced most objections (although see Kabat 2008).

More than the carcinogenicity debate, the passive smoking debate exposed explicit industry efforts to create scientific contestation (Glantz et al. 1995). Metaanalyses showed that research sponsored by the industry was unlikely to find that passive smoking was hazardous, whereas most independent studies had found that it was (Barnes and Bero 1998). Existing studies, then, provide two similar stories about two separate debates: carcinogenicity in the 1950s and early 1960s and passive smoking in the 1980s.

What had happened between these two contentious episodes? The canonical accounts say very little. Kluger's (1996) definitive account devoted 7 of 804 pages to the TWG, which operated between 1967 and 1978 and will occupy much of this 
article. Brandt's Cigarette Century devoted more than 100 pages to science, but the few lines about the 1970s are in the section "Politics." Overall, 1970s research was portrayed as an addendum to the political efforts of the industry, not as a period of important research efforts or achievements. The following quantitative analysis suggests that the period merits a second look.

There are other reasons to seek a general overview of this literature. Previous studies have explained all hurdles in the development of the scientific literature in purely social terms while accepting its successes as good science. Bloor (1976) warned of such a "sociology of error" in which scientists are presumed good and honest until we discover that some erred. Retrospectively, we must not attribute errors to "social factors," such as greed and opportunistic funding, unless we are willing to do so for other sociological problems, such as attributing religion's success to god and only its weakening to social factors. Bloor's solution was to explain both sides of the controversy in social terms, which he called symmetry. The symmetry offered here, ${ }^{1}$ following Latour (1987), has difficulty distinguishing between "social factors" and "pure science" and assigning greed and deceit to one side of a controversy. Rather, as the Latourian formulation suggests, I hope to explain all periods and literary camps in this history with the same tools, assuming that scientists pursue success as well as truth, regardless of whether we should call these motivations "social" or "pure." To prevent the fallacy Latour (2005:164) described as "society standing in the way of sociology," sociology must trace social factors in each case anew, not predetermine what they should be.

The prevailing explanation for the objections to tobacco's carcinogenicity claim focus on industry dollars. This focus is quite anachronistic. Mid-twentieth-century cancer research was truly in a poor state; most arguments against tobacco's carcinogenicity made sense and often had no relation to industry funding (White 1997; Mukherjee 2010). Articles from the 1950s and 1960s that promoted the carcinogenicity claim never argued that the claim was consensual or ignored for political reasons (as climate change scholars often did in the 1990s; e.g., Charlson et al. 1992).

In contrast, the current study attempts to follow science in its making (Latour 1987) rather than to evaluate it retrospectively from the present (Pickering 1993). This study thus limits itself to the clearly time-stamped evidence of scientific papers. This approach suggests a methodology that focuses on the artifacts of science: articles and their citations. Using Leicht and Newman's (2008) modularity algorithm validated as a contestation measurement tool (Shwed and Bearman 2010), the analysis finds the 1970s to be the most divisive period in the history of this literature. Analyzing the structural relations between articles and literary camps over time connects the carcinogenicity debate of the 1950s and 1960s with a seldom-told story of the 1970s quest for a safe cigarette (although see Parascandola 2011; Fairchild and Colgrove 2004), which, in turn, paved the way to reunite the literature around the hazards of passive smoking. Correcting the historiography of this case offers a more nuanced and realistic narrative than the cautionary tale against science-industry collaborations. Tracing the social associations of science making, rather than seeking the "Social" (Latour 2005), develops such a narrative. The next section describes the methodology that enables it and presents its findings. 


\section{Quantitative Analysis: Tobacco Studies in the 1970s}

\section{Methods}

In the twenty-first century, we know so much about the tobacco industry's malfeasance and the context of science making in this case that this article sacrifices some context to focus on science. It views the dynamics of science as they unfold rather than retrospectively (Pickering 1993), relying on a quantitative method free of userspecified parameters. Network analyses of science usually focus on coauthorship networks (e.g., Moody 2004) to reveal the underlying social structure of scientists, citations as prestige measures (e.g., White 2000), citations between journals as indicators of affiliation (e.g., Rosval and Bergstrom 2010), co-citations as indicators of content similarity (e.g., Lenoir 1979), keywords and concepts as ties between articles and scientists (Evans 2010), and combinations of these (Vilhena et al. 2014). Each of these approaches has its advantages and disadvantages. All share a requirement for analysts' judgment calls on various levels, such as what is a strong enough tie or what is a significant number of collaborations. In attempting a quantitative formulation of a symmetrical method, this study attempts to minimize such decisions and to force the analyst to use the very same frameworks for all periods and literary camps. $^{2}$ Thus I analyze scientific articles and the simple citations between them as directed indicators of relevance. Rather than interpreting science, it is represented at every given moment as a citation network, and the networks' structure is analyzed. Peer-reviewed scientific articles generate directed (from citer to cited), unvalued networks of articles tied by citations. Such networks require minimal discretion from analysts regarding the thresholds for tie strength or similar decisions.

The analytical strategy combines quantitative modularity analysis (Shwed and Bearman 2010,;012) and qualitative labeling (Navon and Shwed 2012). Modularity analysis using Leicht and Newman's (2008) algorithm for directed networks identifies crucial moments of contestation or consensus making and meaningful literary camps in the literature. It also identifies the relationships between these camps (nested or split). Qualitative labeling of these camps allows for a retelling of the literature's main themes, its development, and the relations between research themes. Both of these strategies serve as safeguards against the automatic reproduction of the canonical story when not supported by the data. The entire procedure consists of five stages. First, using Thompson Reuter's ISI Web of Science, I extracted all peer-reviewed articles published in the twentieth century using the search terms (Tobacco or Cigar* or Nicotine or Smoking) and the terms (Cancer or Carci*) and represented them as a network. These articles and their citations define the broad data set.

Second, this data set was sliced temporally to observe science in its unfolding. Determining the periodization ex post enforces analysts' view of the field's history. Thus I employ Shwed and Bearman's (2010) dynamic moving windows: data are handled by means of a moving window, but each window's temporal scope is set by the changing structure of citations. When the articles in a given year engage in a contemporary debate, the observation period will be short, and when the articles published in a different year engage in a historically deep debate, the observation period will be longer. Specifically, for each year $Y$, I extract a distribution of citation 
ages, defined as the difference between $Y$ and the year of publication of each paper cited in $Y$. This distribution's median serves as the window width for year $Y$. The window contains a population of focal papers that are relevant for the year at the end of the window. Older papers that were cited by any focal paper are also included to keep influential papers in the analysis regardless of their age; the papers cited by these are not included. Thus this second stage turns the broad data set into a series of 53 overlapping temporal networks, each network containing the scientific debate relevant for the articles at the end-year of the network. Data on the 19 temporal slices analyzed in this article are presented in Table 1.

Third, these temporal slices were subjected to a community detection algorithm that finds meaningful subgroups that represent schools, camps, or research areas. The algorithm also evaluates the salience of those divisions for the overall structure as the modularity metric (Leicht and Newman 2008). Modularity is the fraction of citations that fall within groups of the "best" (most modular) divisions minus the expected such fraction if citations were redistributed at random. ${ }^{3}$ When scaled for network size, modularity reveals turning points in the history of scientific literature (Shwed and Bearman 2010); this may be considered an indication of black boxing. Specifically, an increase in scaled modularity indicates that internal divisions between communities, or literary camps, have become more salient and observable, or less black boxed, whereas a decline in scaled modularity indicates convergence to a common core and a concealment of internal divisions.

The algorithm works iteratively, dividing the network into two groups by the direction of the leading eigenvector. Each group is further divided into 2, and so on for as long as these divisions add information about the structure. This property is quantified by the modularity metric (see earlier) at each stage. Thus the algorithm identifies network communities-in our case, subfields within tobacco and cancer research-and the salient cleavages between them, which are discernible from the iterative-hierarchical structure of division. The third stage of the analysis provides, for each temporal network, an allocation of each article into a community, the nested structure of these communities, and the salience of each division. ${ }^{4}$

In the fourth stage, redundant communities are collapsed back to generate meaningful communities. Maximizing modularity may create many communities, some of which are meaningful, whereas others are fragments of a meaningful community. For example, an article on throat cancer in Romania that cites three other Romanian articles would define a community of four papers, most likely nested within another community of, for instance, regional throat cancer reports. Such minor divisions are less relevant for understanding the main debates in a given body of literature. In addition, modularity tends to misallocate articles in small communities with a low average degree (see Fortunato 2010). To distinguish between meaningful and miniscule divisions, the modularity metric was recorded at every iteration of the algorithm. When the modularity of a given division was significant, resulting communities carried a meaningful variant or topical focus of the literature. However, when it was miniscule, the resulting two communities were treated as one. This approach requires determining a "significance" threshold. In the absence of previous literature (although see Navon and Shwed 2012), a threshold of 0.01 was used. Divisions that contribute less than 1 percent to modularity are 
Table 1: Properties of Dynamic Windows

\begin{tabular}{cccccccc}
\hline $\begin{array}{c}\text { Calendar } \\
\text { Year }\end{array}$ & $\begin{array}{c}\text { Published in } \\
\text { Calendar Year }\end{array}$ & $\begin{array}{c}\text { Median } \\
\text { Citation Age }\end{array}$ & $\begin{array}{c}\text { Focal } \\
\text { Period }\end{array}$ & $\begin{array}{c}\text { Published in } \\
\text { Focal Period }\end{array}$ & $\begin{array}{c}\text { Total } \\
N\end{array}$ & $\begin{array}{c}\text { Scaled } \\
\text { Modularity }\end{array}$ & $\begin{array}{c}\text { Mean } \\
\text { Degree }\end{array}$ \\
\hline 1965 & 6 & 8 & $1958-1965$ & 85 & 135 & 0.080 & 5.66 \\
1966 & 14 & 6 & $1961-1966$ & 78 & 133 & 0.092 & 4.03 \\
1967 & 9 & 6 & $1962-1967$ & 60 & 135 & 0.102 & 3.66 \\
1968 & 12 & 7 & $1962-1968$ & 72 & 148 & 0.097 & 3.82 \\
1969 & 12 & 9 & $1961-1969$ & 97 & 167 & 0.090 & 4.39 \\
1970 & 11 & 8 & $1963-1970$ & 84 & 164 & 0.103 & 3.62 \\
1971 & 16 & 8 & $1964-1971$ & 89 & 173 & 0.114 & 3.26 \\
1972 & 19 & 7 & $1966-1972$ & 93 & 163 & 0.130 & 2.83 \\
1973 & 10 & 10 & $1964-1973$ & 118 & 203 & 0.110 & 3.24 \\
1974 & 19 & 5 & $1970-1974$ & 75 & 158 & 0.130 & 2.49 \\
1975 & 16 & 9 & $1967-1975$ & 124 & 214 & 0.115 & 3.01 \\
1976 & 11 & 5 & $1972-1976$ & 75 & 167 & 0.142 & 2.29 \\
1977 & 22 & 8 & $1970-1977$ & 124 & 218 & 0.127 & 2.73 \\
1978 & 20 & 6 & $1973-1978$ & 85 & 207 & 0.145 & 2.22 \\
1979 & 17 & 4 & $1976-1979$ & 70 & 165 & 0.163 & 2.04 \\
1980 & 20 & 7 & $1974-1980$ & 125 & 229 & 0.141 & 2.32 \\
1981 & 40 & 4 & $1977-1981$ & 109 & 198 & 0.150 & 2.15 \\
1982 & 36 & 4 & $1978-1982$ & 123 & 214 & 0.148 & 1.97 \\
1983 & 50 & 5 & $1979-1983$ & 163 & 285 & 0.131 & 2.65 \\
\hline
\end{tabular}

Temporal coverage of analyses selected for presentation.

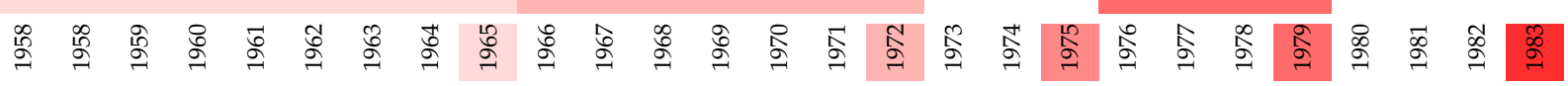

Notes: The table presents, from left to right, for each calendar year, the number of published articles about smoking hazards, the median citation age in this annual group of articles (indexing the temporal scope of scientific discussion), the resulting focal period (which ends at the calendar year and begins median-citation-age years back from the calendar year), the total number of focal articles published in this period, the total number of papers in each observation window (focal papers and older articles, cited by the focal papers), the scaled modularity (represented in Figure 1), and the mean degree of the network. The analysis presented was conducted for every year between 1965 and 1984 . Four of these analyses were selected for presentation in the figures below; selection was based on temporal coverage and other reasons derived from Figure 1 and elaborated in the text. Analyses selected for presentation are shaded in gray in the upper panel. The bottom panel of the table illustrates the temporal coverage of the analyses selected for presentation in the figures below; each calendar year is shaded according to the selected analyses in which it appears. No years are missing from the analyses selected for presentation. Some years (1967-1972 and 1979) are included in two separate figures, as indicated by double shading.

considered insignificant. ${ }^{5}$ The empirical analysis suggests that this threshold is conservative because differences between neighboring communities often seem forced. However, this method also assures that no meaningful community is ignored and collapsed into another. Thus the fourth stage of the analysis produces a shorter 
list of communities than the one provided by Leicht and Newman's algorithm, although it is still free of analysts' discretion or interpretation.

The fifth and final stage of the analysis, community labeling, is the only stage in which the analyst has some discretion that may influence the results of the analysis. I hedge against this influence with explicit procedures. In this stage, I have read the top-cited 4 to 10 articles in each community and labeled the community based on the common interest in these articles. Thus, at the end of the procedure, the literature is divided into overlapping temporal slices, each going back from a specific calendar year and represented as a citation network. Each network is represented as a hierarchical tree that maps the division of network communities, quantifies the salience of each division in that tree, and names communities based on their content. The tree expresses the main debates and division for each period. Comparing such figures for different temporal slices expresses the literature's dynamic. In the next section, I outline the puzzle in this literature that becomes observable through modularity analysis and employ the described procedure to solve it.

\section{Results}

Figure 1 plots the scaled modularity metric of every temporal network, representing an overview of the intensity of debates in the study of smoking hazards (see Shwed and Bearman 2010). It tracks the well-documented consensus formation toward the 1964 U.S. Surgeon General's report as a decline in scaled modularity. Similarly, the figure shows the consensus that formed in the 1980s on the hazards of passive smoking. Surprisingly, and contrary to existing accounts, the figure suggests that the 1964 consensus did not last until the passive smoking argument sparked a debate; scaled modularity increased during the mid-1960s and peaked between 1976 and 1979. This increase represents scientific contestation or fragmentation. Throughout the 1970s, contestation levels were unstable, yet they remained high even at their local ebbs. Only in the 1990s did scaled modularity levels return to their pre-1970s levels. The consensus formed in the 1980s, then, did not end a debate that was reopened with the discovery of passive smoking. Rather, passive smoking united literature that became fragmented in the 1970s. Recall that the existing historiography of the case largely overlooks the scientific debate of the 1970s. The quantitative scientometrical analysis in Figure 1 suggests that this historiography merits a revision. To explore this fragmentation of the literature in the 1970s, we should look deeper into its structure.

To extract meaning from the structural divisions of the literature, I present the modularity calculation process as a hierarchical tree, where each level represents a division. This approach allows me to distinguish between the most salient, primary division in the literature at a given time and its subdivisions. For example, Figure 2 provides a map for the scientific debate in 1965, when the median citation age was eight; thus the figure represents all articles published between 1958 and 1965 as well as other articles cited by these articles. The full network is labeled " $G$ " at the bottom. The first division produces a modularity score of 0.33 (note that whereas Figure 1 indexes contestation and plots scaled modularity, the following figures refer to raw modularity scores). Then, community 0 was further divided 


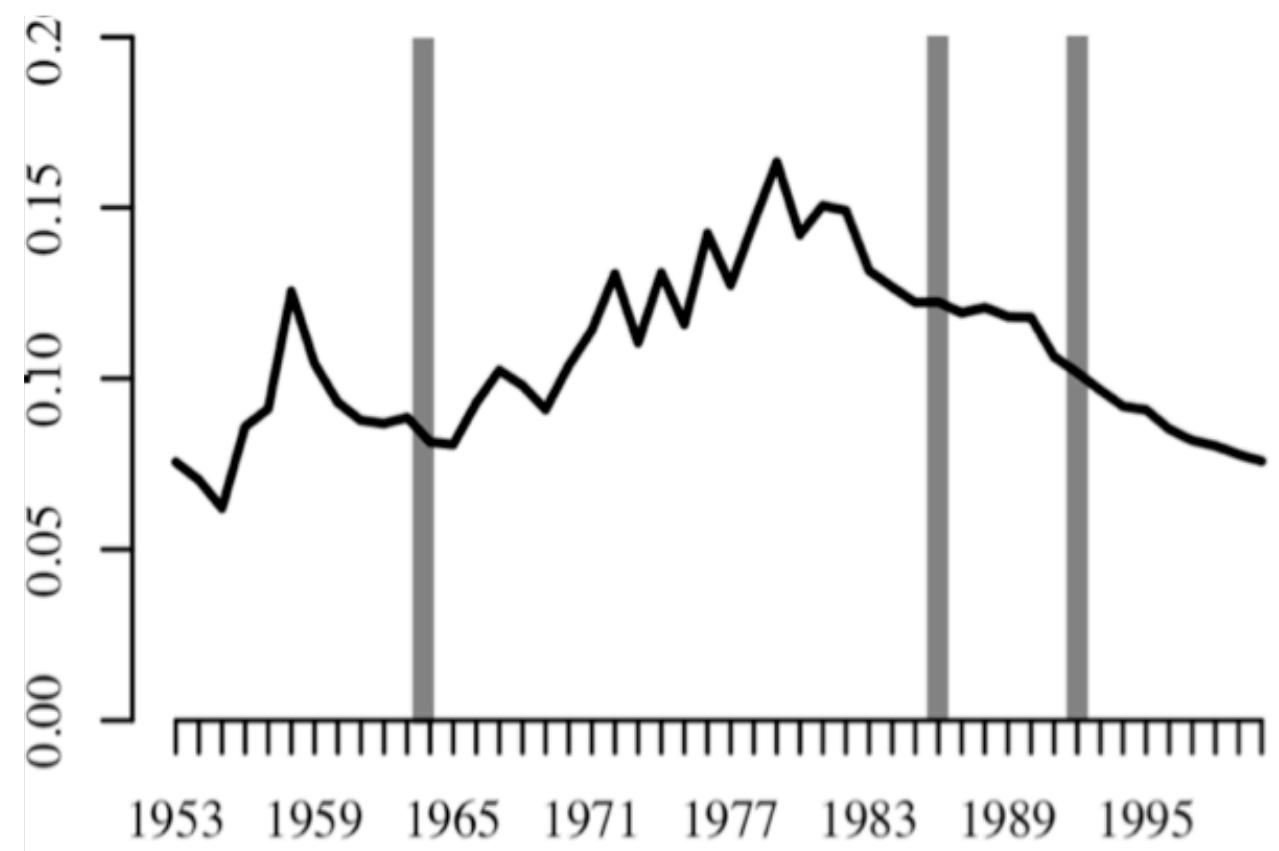

Figure 1: Modularity analysis of smoking hazards research. The dark line, corresponding to values on the $Y$ axis, represents modularity scores scaled for logged network size. High levels of this measure correspond with contestation, whereas a declining scaled modularity refers to consensus formation. The $X$ axis marks the year at the end of the observation window, and gray bars mark three important consensus reports: in 1964, the first U.S. Surgeon General report on the hazards of smoking; in 1986, reports by the IARC, NAS, and the U.S. Surgeon General; and in 1992, reports by the EPA.

into two communities of 30 and 38 papers, adding only 0.01 to the modularity score. These communities were mathematically indivisible by the modularity algorithm. The other branch of the primary division, community 1, was divided into two communities, contributing 0.03 to modularity. Each of the communities created by this division (1 and 3) was further divided, but these divisions contributed even less than 0.01 to the modularity. Thus, the articles in communities 5 and 6 were considered part of community 3. Similarly, community 4 was treated as part of community 1. Ignoring these final, insignificant divisions and acknowledging only four of the seven communities produced by the algorithm accounts for 99.7 percent of the modularity score plotted in Figure 1.

Common themes in the top-cited papers in each community were used to label the communities. In the 1965 network, the four communities are "Old Debates" (communities 3, 5, and 6), "Causal Debate" (communities 1 and 4), "Carcinogenicity Proof" (community 0), and "Call for Research on the Safer Cigarette" (community 2). The differences between the communities divided in the secondary divisions are subtle, whereas the primary division has a temporal logic that distinguishes between previous and contemporary research; the former is centered on epidemiology and the latter on laboratory studies. This is an overview of the research in 1965, when modularity was extremely low (see Figure 1) and the literature was consensual. 


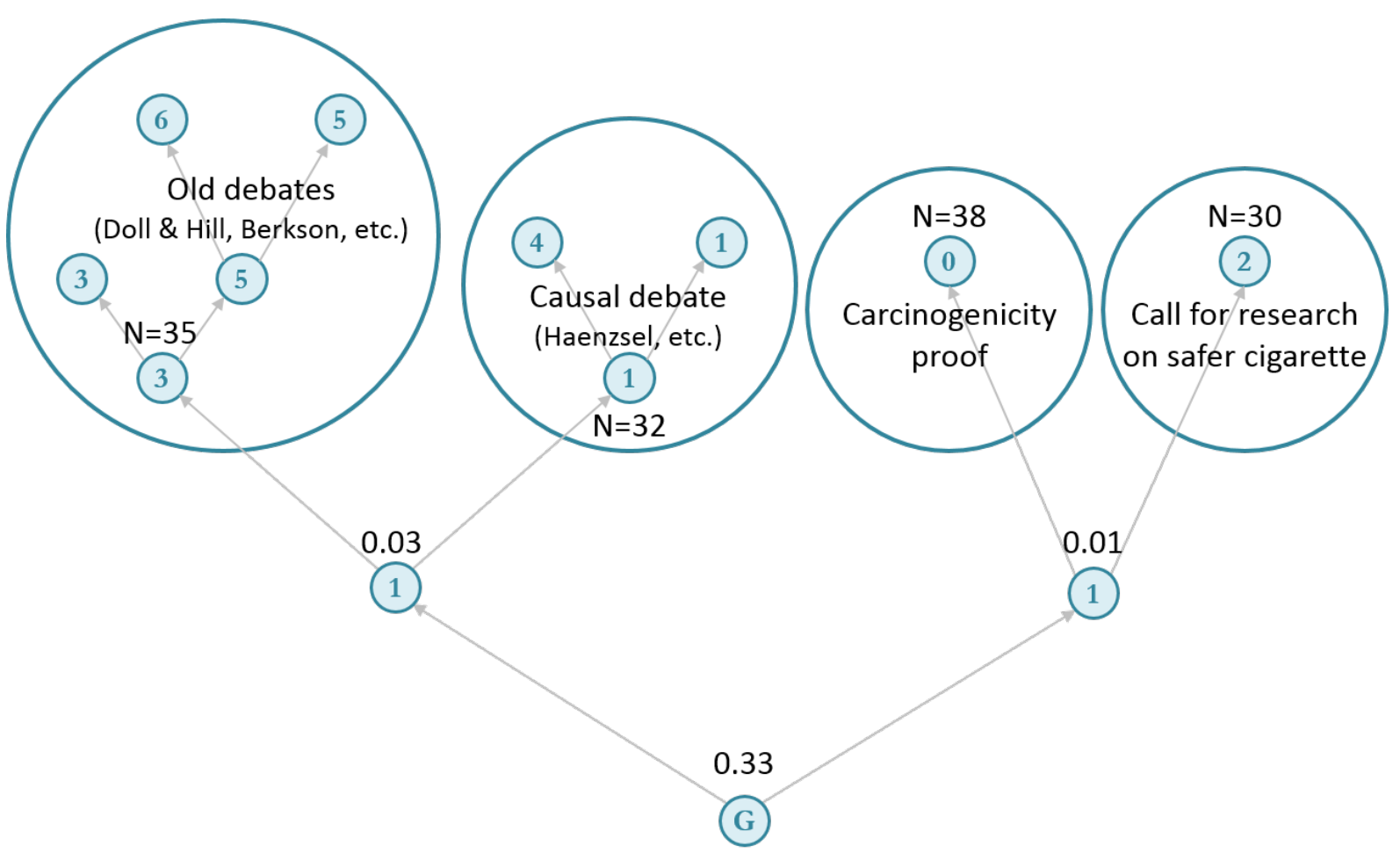

Figure 2: Communities in the 1965 Citations Network. Community numbers are arbitrary. Decimal fractions refer to the division's contribution to overall raw modularity, and $\mathrm{N}$ refers to the number of scientific articles in every final community-indivisible or where further divisions' modularity contribution is less than 0.01 .

Figure 2 provides a starting point to track the course of research in the 1970s (while also demonstrating the interpretation of such graphs). Such figures were produced for every year between 1965 and 1985. The citation networks throughout the 1970s are similar in revealing the primary division of a "safer cigarette" venue from other papers. For the current demonstration, Figure 3 presents four selected temporal slices. These selected years and their properties compared to unselected years are displayed in Table 1. The years' selection was based on Figure 1. The network labeled 1972 (for focal papers published in 1966 to 1972; panel A) is the first local modularity peak; 1975 (for 1967 to 1975; panel B), a local ebb in the modularity analysis, shows that local fluctuations do not hide important variation; and 1979 (for 1976 to 1979; panel C) is the peak of contestation. Panel D (for 1979 to 1983), a few years before the 1986 reports of the hazards of passive smoking, shows the formation of the consensus on passive smoking. Together, they cover the period to tell a story.

Put succinctly, the 1970s contestation concerned the quest for a safer cigarette, often described as a wild goose chase (Davis 2007:195; Parascandola 2005a). Panels A to $C$ show the primary division between the harm reduction camp and all other research communities. In panel $\mathrm{A}$, in marked contrast to Figure 2, the primary division was between papers that sought a safer cigarette and other research agendas. The 62 papers in the safer cigarette camp were further divided into two commu- 


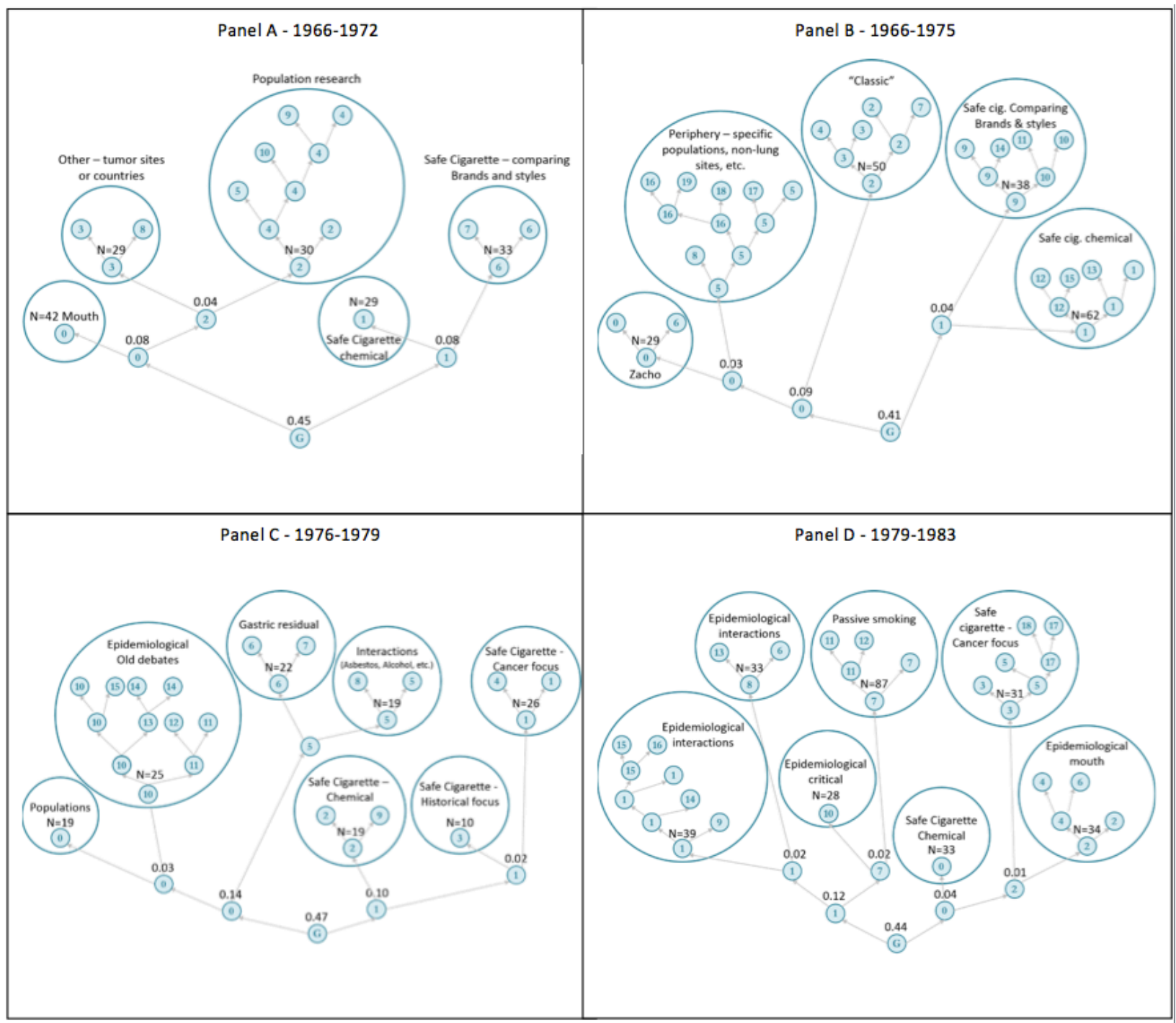

Figure 3: Communities in the 1970s. Community numbers are arbitrary. Decimal fractions refer to the division's contribution to overall modularity, and $\mathrm{N}$ refers to the number of scientific articles in every final community-indivisible or where further divisions' modularity contribution is less than 0.01 . Throughout the 1970s, the primary division clearly distinguishes the camp engaged with developing a safer cigarette from the rest. This logic of division disappears in panel D, two years after the first publication of passive smoking epidemiological evidence.

nities, whereas the rest of the network was divided into three communities by the methodology or cancer sites. This dividing logic prevailed throughout the next decade. Panel B, with a larger network that represented a longer observation period, revealed a similar primary division. The main difference between the modularity peak in panel A and the ebb in panel B is the division within the safer cigarette camp, which was less salient in 1975 . Throughout the 1970s, the primary division remained robust to the fluctuations of Figure 1. 
The primary division remained the same in panel C, when modularity was at its all-time peak. The safer cigarette project developed significant internal divisions into three groups that contributed 0.12 to the total modularity. Yet the overall structure of meaningful divisions in the literature was remarkably similar in panels A through $C$ and in other years not shown (see Table 1). Note that this characterization of the primary division is robust to all of the variation throughout the 1970s in network size, temporal scope, and modularity.

This dividing logic faded away with the 1970s. Panel D represents 1979 to 1983: for the first time since 1970, the primary division of the network did not distinguish the safer cigarette camp. Community 2, focused on oral cancer, was on the same side of the primary division as the harm reduction communities. The salience of the cleavage between the safer cigarette and the remainder of the literature diminished. By 1983, we see a new, much larger community circumventing subcommunities 7,11 , and 12 with 87 papers, compared to 39 in the five subcommunities of the second-largest community. This new, large community was centered on passive smoking. The shift from panel $C$ to panel $D$ represents the crucial transition from the 1970s to the 1980s, from a debate about harm reduction to a growing consensus about the hazards of passive smoking.

To highlight this important transition, both citation networks are presented in Figure 4, with colors marking the articles' communities. The figure provides a different way of plotting the relationships between different research communities, representing each publication as a node in this network, with colors marking communities. The literature in 1976 to 1979, on the left-hand side, shows clearly segregated communities that are representative of previous years in that the safer cigarette communities are somewhat clustered together. Square nodes represent articles first-authored by Ernst Wynder; these are centered on the three safer cigarette communities and on the "residual" community. The literature in 1979 to 1983, on the right-hand side, is different: one of the safer cigarette communities disappeared, and, overall, communities were more intertwined. Crucially, the yellow community, centered on passive smoking, was the least segregated; it bridged most other communities and provided the core of the consensus that would emerge and reunite the literature by 1986 . Note that this property of the passive smoking community could not be found in any one article-it is a structural property of the citation patterns at the literature level, revealed by the quantitative analysis.

This overview highlighted the importance of ETS in terminating the debate (Bayer and Colgrove 2002) but also revealed something new: an association between ETS and the harm reduction debate. The story of harm reduction is a precursor of the ETS research agenda. Recently, parts of the harm reduction story were recounted for their own historical worth (Fairchild and Colgrove 2004) or as case studies of science-industry collaboration (Fields and Chapman 2003; Parascandola 2005a, $2005 \mathrm{~b}, 2011)$. However, previous accounts did not identify the association of harm reduction with passive smoking. The quantitative analysis provided here embeds harm reduction in the general history of tobacco hazards research. It reveals two transitions: from experimental cancer production in earlier periods, embedded in a larger field, to the separate harm reduction effort in the 1970s, and then to a reunification of the literature in the 1980s around passive smoking. Observing 
1976-1979

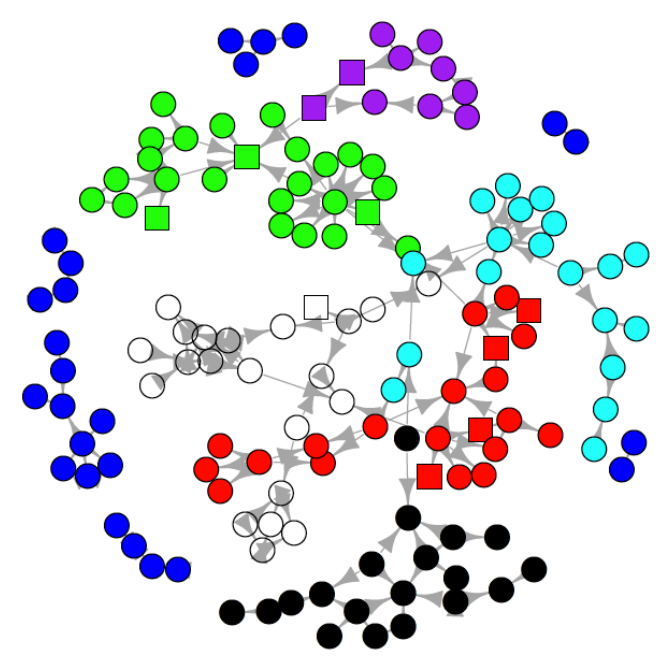

1979-1983

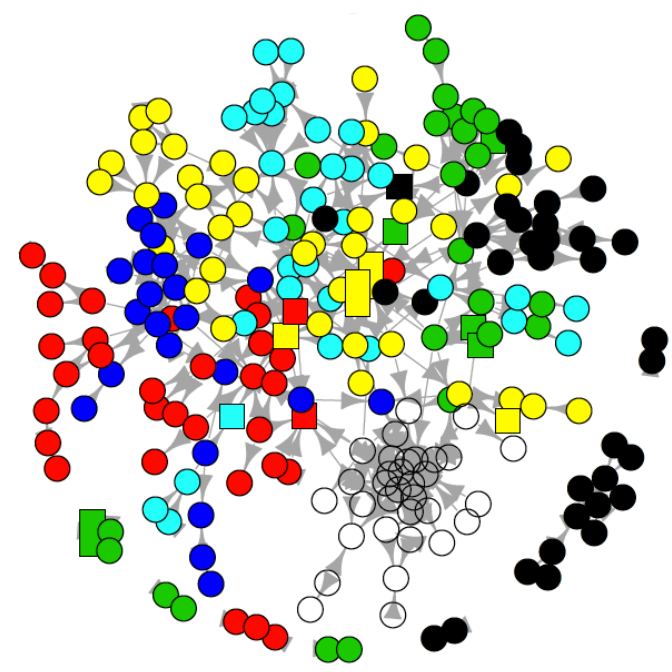

\begin{tabular}{|l|l|l|l|}
\hline \multicolumn{3}{|c|}{ Legend } \\
\hline Safe Cigarette - Chemical & & Interactions & \\
\hline Safe Cigarette - Cancer & & Old Epidemiological debates \\
\hline Safe Cigarette - Historical (in 1979) & & Specific populations & \\
\hline Passive smoking (in 1983) & & Oral/Gastric cancers (+residual) & \\
\hline
\end{tabular}

Figure 4: Papers and their communities in 1979 and 1983. Circles represent papers published in the observation period or cited by those papers, connected by citations, laid out with the Fruchterman-Reingold algorithm. Papers first-authored by Ernst Wynder are marked by a square, and papers first-authored by Takeshi Hirayama or Dimitri Trichopoulos are marked by a rectangle. Colors represent communities. Isolates were removed from the graphical presentation but not from the analysis. The high modularity in 1979 is apparent in the clear segregation between communities, which are well defined, except for the blue community of old epidemiological debates, which comprises old citations and a residual category. By 1983, communities are more intertwined, marked by the passive smoking community (yellow), which bridges the passive smoking communities and diffuses through much of the network. By 1983, the black and green communities of specific populations and the quest for a safe cigarette, respectively, become less defined and present the internal clustering characteristic of a fading community and residuals.

this transition requires quantitative analysis, but a better understanding of these transitions comes when we seek actors' accounts of them. The next section offers an interpretation of the findings, following Ernst Wynder, the "father of tobacco studies" (Pierce 1999), and explaining each period's literature as a product of its previous incarnation. 


\section{Embedding the 1970s between the 1960s and the 1980s}

\section{From the Carcinogenicity Debate to the Harm Reduction Quest}

Ernst Wynder, the first American to correlate smoking and cancer (Wynder and Graham 1950), is a good actor to follow in linking the 1970s harm reduction studies (which he mastered) with the previous period. A leader in both the carcinogenicity debate of the 1950s and 1960s and the harm reduction camp, his actions and relationship with the industry shed light on the dynamics of science and industry. He shifted from being the industry's bitterest enemy to garnering substantial industry funding for harm reduction (Fields and Chapman 2003). Fields and Chapman imply that he "sold out" - they expose multiple industry attempts to use Wynder via funding. However, they provide no evidence that these attempts succeeded.

Reading Wynder's works in the order of their publication provides another option. It reveals Wynder's struggle-not against the industry but against the poor understanding of cancer at the time (Mukherjee 2010). Objections to the initial epidemiological findings led Wynder and, soon thereafter, followers into the laboratory. The scientific community did not envision a plausible biological mechanism that linked smoking and cancer; Wynder and his colleagues showed that it existed. They studied smoking patterns and constructed special machinery to simulate smoking and capture the tar, which they then smeared on mice skin. When the mice produced cancerous moles, in contrast to a control group of mice smeared with similar substances but no tobacco tar, Wynder could convincingly show the existence of a biological mechanism, even if it was not fully understood. Such evidence accumulated in the late 1950s and was first presented in the landmark study of Wynder et al. (1953).

However, the 1953 paper did not convince the skeptics on its own. In the decade between its publication and the 1964 Surgeon General's report that declared a consensus on tobacco's carcinogenicity, science worked as science does, with scientists pursuing knowledge, prestige, status, and funding. Once there was proof of an association between smoking and cancer, new challenges arose: correlation was no proof of causation, and mice skin cancer was no proof of human lung cancer. When Graham, Wynder's mentor, died of lung cancer in 1957, mice studies led Wynder, followers, and competitors to smear tar on rabbits, dogs, hamsters, and other animals, providing the causal claim with a robust animal model. In this decade, Wynder moved from avant-garde to leadership. His findings gradually won wide recognition.

His landmark 1953 study was groundbreaking in associating the animal-model concept with epidemiology, effectively establishing the field of experimental cancer production. Wynder was the center of an apparatus of laboratories capable of such research, employing ever-improving smoking machines, tar extraction methods, and different species (Kluger 1996:429). However, as more and more scholars replicated his findings, he moved on. After associating biology and epidemiology, the next step was to mobilize chemistry. Wynder recruited Hoffmann and began isolating different components of smoke condensate and testing its carcinogenicity. This series of studies is the backbone of the network community labeled "Safer cigarette-Chemical," which prevailed in the 1970s. Those who claimed that there 
were no known carcinogens in tobacco were now faced with newly discovered carcinogenic substances. ${ }^{6}$

The hypothesis of the young medical student Wynder had gone a long way, confirmed by epidemiology and clinical research, supplemented with a biological mechanism, and attached to newly discovered chemical mechanisms. Associating different methodologies, each with new collaborators, Wynder (1997: 689-90) overcame objections with the juxtaposition of multiple methods. He writes retrospectively (about the 1953 paper).

Biological plausibility added a significant dimension to the criteria for causality of the association of smoking and cancer, i.e., its consistency, its strength, its specificity, its temporal relation, and its coherence.

The quantitative analysis showed that until 1964, Wynder was in the center of a community united by the effort to prove that smoking is cancerous. When he explained the role of laboratory studies of carcinogenicity at that time, he again offered an egalitarian division of labor with an array of approaches, consistent with his articles' (embedded) network position (Wynder and Hoffmann 1963: 337):

The purpose of laboratory studies... was not to establish cancer causation for man, which we believe in our present setting to rest primarily on human evidence, but rather to determine whether tobacco smoke condensate is carcinogenic to animal tissue. ... If supported by human data, then it could conceivably be inferred, though not established, that the substances responsible for the carcinogenic activity to animal tissue might have a similar action on human tissue.

Two things are striking about this quote. First, it is quite different from the former, retrospective evaluation. In 1997, Wynder positioned biological plausibility as adding a significant dimension that enabled causal claims, whereas in 1963, he positioned it as merely supporting human evidence. More notable (and perhaps the reason for this discrepancy) is that when Wynder writes that the goal is not to establish causality, he means the opposite. Considering the timing of the review (after the British consensus declaration but before the U.S. Surgeon General's report), the quote may be rephrased as "when we showed correlations of smoking and cancer, everyone refused to accept it for lack of a biological mechanism. When we found the biological mechanism, statisticians refused to accept it because mice are not human, and chemists were not convinced because we did not find an agent they knew as carcinogenic. We now offer a full report of biological and chemical carcinogenic mechanisms related to tobacco smoke." Such a division of labor, positioning animal studies as an equal partner in a network of proof, is common in earlier (pre-1964) publications.

As multiple types of evidence were mounted, old objections lost steam. The modularity peak presented in Figure 1 in 1956 to 1958 confirms this; evidence had been there since 1953 and provoked a backlash until 1958, but the backlash was not as robust as the evidence. During the 1950s and 1960s, the balance between promoters and objectors of the carcinogenicity claim changed, with Wynder and his 
team shifting from being a ridiculed minority in the late 1940s to being celebrated leaders in the early 1960s (see Brandt 2007:131-49).

This is the point of the story where Brandt and others turned silent on science, returning to it only in the 1980s to discuss passive smoking. The quantitative analysis alerts us that Wynder and colleagues did not rest in the 1970s. They shifted their attention from the hazards of existing smoking products to developing new, potentially less hazardous cigarettes. In doing so, they created the central debate in the 1970s. Although we know today that they ultimately failed in producing a safer cigarette, the articles that reported progress toward this dominated the scientific literature of the time, which was published in venues such as JAMA and Science. Institutionally, this group materialized in the TWG, founded by Wynder through the National Cancer Institute (NCI). This group is at the heart of the debate that split the literature. Many of the leading scientists of the time were members of the group (Kluger 1996), yet it is hardly described in the literature (notable exceptions are Fields and Chapman 2003; Fairchild and Colgrove 2004; Parascandola 2005a,;005b,;011).

In retrospect, commentators such as Parascandola imply that the shift from a unified literature focused on tobacco hazards into a literature split on harm reduction was a result of Wynder "selling out" for industry funds. In real time, however, Wynder's work revealed that it was his initiative rather than the industry. A few months following the earlier cited review, he published another review of laboratory studies. The same authors, writing about the same topic, offered a very different tone. Contrast the previous quote with the next, from an article titled "Objective of Laboratory Studies" (Wynder and Hoffmann 1964: 251):

To determine whether various tobacco and tobacco smoke products might prove to be carcinogenic, ... which of the components may be held primarily responsible. ... Once such components have been identified, attempts might then be made to investigate the possibility of their removal or reduction.

Within a few months, the goal of laboratory studies was to find which components of tobacco smoke could be reduced to prevent carcinogenicity rather than to support a proof. This quote reads more like the retrospective quote from 1997, suggesting that Wynder's view of the role of laboratory studies changed around that time. The timing of this change should indicate its reasons, but Wynder and Hoffmann (1964: 252) leave no guesswork for the alert reader, stating,

The Advisory Committee to the Surgeon General... indicated smoking as a cause of lung cancer. ... It is only in the laboratory, however, that tumorigenic components, antitumorigenic agents, ... can be investigated.

After the Surgeon General declared that smoking causes cancer, finding which component was responsible became an obvious next step. The article continued to review tobacco products, experimental methods, smoking machines, techniques, and the results of previous studies. The postscript was a manifest for research toward a safer cigarette: 
Public health authorities... may well propose that public education on this issue should be extended so as to discourage smoking. ... Since complete cessation of the human smoking habit appears not to be in the realm of reality, at least not in the foreseeable future, a reduction of the tumorigenic activity of tobacco precuts seem to be the only possible and practical alternative. To achieve this goal will require continued efforts of scientists of independent research groups, as well as the cooperation of the tobacco industry, public health authorities, and the public at large. (Wynder and Hoffmann 1964: 435)

Wynder set the agenda for the next 15 years. Rather than emphasizing the heterogeneous network he weaved (as in the 1963 paper), he emphasized the unique apparatus he mastered: laboratories of carcinogenicity. He explicitly argued that this was the only way to go, and a safer cigarette was the "only possible and practical alternative." He framed the new problem while making several new, extrascientific associations-to the industry, authorities, and the public. Note that at this point, Wynder had not received industry support (Parascandola 2005a), but he called on the industry to become a part of his effort.

What might explain this change? The new associations Wynder declared while stating a new scientific goal offer a fine example of translation (Callon 1986). The previous goal-proving the carcinogenicity of tobacco-was in direct conflict with the powerful industry. The safer cigarette quest, on the contrary, allowed for translation between public health and the industry's interests. The industry wished to alleviate health concerns and keep selling, whereas health authorities wished to improve public health and reduce its expenditures. Wynder bridged the two and alleviated their contradictions with the vision of a safer cigarette. He had his own interests, of course; once the carcinogenicity claim was accepted, laboratory studies' central role in translating "soft" epidemiological findings into "hard" evidence was no longer required.

Wynder and Hoffmann's quote from their 1964 review explicitly states that the controversial move toward a safer cigarette was a response to changes in the ecosystem of the field. They were forthcoming; the TWG was only initiated three years later, and meanwhile, laboratory studies were losing their ground. This change is evident in the Surgeon General's reports. In 1964, the committee listed ten central topics. Half of these, notably the first two, demanded carcinogenicity laboratories (U.S. Surgeon General's Advisory Committee on Smoking and Health 1964:14). In 1967, these were refined into four precise research questions, only the last of which had any bearing on laboratory studies (4-5). In the aftermath of the acceptance of the carcinogenicity claim, laboratory studies were losing ground.

The quantitative analyses showed that laboratory studies' associations with the remainder of the literature were severed, which had been apparent in the rising modularity since the mid-1960s. On the contrary, new associations with the industry and health authorities could position laboratory studies as a strong, independent endeavor that could save the lives of thousands. The safer cigarette transformed laboratory studies of carcinogenicity from a central part of old literature into demarcated novel literature. 
In doing so, the safer cigarette harnessed industry funds for public health goals. Some view this as an industry stunt to obtain legitimacy, but this view is only valid retrospectively. This was no industry stunt because it was not the industry's doing. Harnessing health authorities and the industry for the TWG guaranteed a cash flow to Wynder's newly founded American Health Foundation (AHF), which employed hundreds of researchers and held the most comprehensive private repository of knowledge on smoking hazards (Kluger 1996:422). A private institute freed Wynder from industry attempts to control him through his supervisors (see Fields and Chapman 2003:572). Finally, to an administration trapped between taxpaying tobacco growers, addicted smokers, and a growing toll of smoking-related diseases, he offered hope for a quick reduction in the epidemic proportion of lung cancer by making the harmful product less harmful.

With explicit support from the federal administration, the industry could not refuse to donate its share. Industry scientists joined the TWG's discussions, and industry funds bought equipment and built research institutes. However, the industry could not prevent publications, as it did in Wynder's previous job (Kluger 1996:423). Industry scientists, monopolizing the product design know-how, were a small minority on the TWG (Gori 2000:49; Parascandola 2005a, 2005b:339) and did little more than note-taking (Kluger 1996:427). Parascandola and others who imply that the TWG was an industry stunt seem to rest more on what is known about the industry's aspirations than on actions. Perhaps the best proof that the TWG was not an industry stunt is its unanticipated result: ETS, or research into passive smoking.

\section{From the Safer Cigarette to Secondhand Smoke}

The importance of the ETS research agenda cannot be overstated. Evidence that tobacco smoke is an environmental hazard, first published in 1981, completely changed the terms of the debate (Brandt 2007:279-315; Bayer and Stuber 2006). Toying with a safer cigarette may help those who choose to risk themselves, but if they emit an environmental risk, cessation and control are in order. Although some still argue that these hazards were exaggerated (Kabat 2008), no one denies that the notion was crucial in mobilizing activists, scholars, and legislators for action that transformed the social meaning of smoking. The quantitative analysis also showed that the emergence of passive smoking terminated the 1970s debate. From where did it emerge?

History had marked Hirayama's (1981) study of Japanese smokers' wives as the turning point in the debate. This, too, was supported by quantitative analysis that placed Hirayama's paper at the center of the largest community, which bridged all other communities. However, Dimitrios Trichopoulos published similar results at the same time. Figure 4 marks Hirayama's and Trichopoulos's first-authored papers in a rectangle and Wynder's with a square. Note that in the network of 1975 to 1979, no paper was led by Hirayama, ${ }^{7}$ and Wynder's first-authored papers are present in all three safer cigarette communities as well as in the red community, which combines a residual category, oral and gastric cancer research. In 1979 to 1983, there are three rectangles: Hirayama's and Trichopoulos's papers at the center of the figure in yellow and an older article by Trichopoulos allocated to the safer cigarette 
green community. Wynder is less present in this network; his papers are in the large new passive smoking community, in the main remaining safer cigarette community in green (with Trichopoulos), and in the pale blue and black communities, studying interactions and specific populations. Passive smoking modified the literature and its dividing logic as it emerged from the safer cigarette communities.

This association rests on more than Figure 4 (or, to anticipate, Figure 5). The very first sentence in Hirayama's article motivated the study with the finding that "mainstream" and "secondhand" smoke both contain carcinogens. Hirayama cited two articles to support this notion (Brunnemann, Yu, and Hoffmann 1977; Brunnemann and Hoffmann 1978). All authors of these papers were related to the TWG, which also funded these studies (Gori 2000:Appendix D).

Four years before the epidemiological studies of the 1980s that showed the hazards of passive smoking, Hoffmann, Brunnemann et al. (Brunnemann, Yu, and Hoffmann 1977; Brunnemann and Hoffmann 1978) distinguished "mainstream" from "side-stream" smoke in their experiments. Their study was a tiny building block for a safer cigarette that investigated the utility of filters. Its goal was to refine the smoke retained by the smoker; therefore the authors separated it from the unfiltered smoke coming out of the cigarette's burning end. To their surprise, they found the latter was far more carcinogenic than the filtered "mainstream" smoke. In conclusion (and likely due to the dismay of industry scientists at the TWG, who had no means of controlling publications), they called for epidemiological research on the hazards of "side-stream" smoke. Hirayama's text acknowledged that the idea of examining the effects of passive smoking came from the TWG's meticulous analysis of smoke components in the 1970s.

Hirayama's connections with the TWG were deeper than article citations. He was Wynder's "close friend" (Stellman 2006) and collaborator. One of the articles he coauthored with Wynder (Wynder and Hirayama 1977) was part of the same funding grant as the first study to examine side-stream smoke, conducted by Wynder's colleagues (Brunnemann, Yu et al. 1977:NCI grant CA-17613). It seems prudent to conclude that Hirayama picked up the discovery of side-stream smoke while collaborating with Wynder on the same grant in the AHF. The meticulous attempt to refine smoke and develop a safer cigarette-usually considered an industry PR success-led to the industry nightmare of passive smoking research.

The research challenges of the 1950s shaped the heterogeneous research network of the early 1960s, and the literature structure in the 1970s was a product of the laboratory studies camp that was forged in the 1960s. In the 1980s, the literature was reunited around passive smoking, but this new concept came from the otherwise futile attempt to develop a safer cigarette. Figure 5 represents the 100 papers that were part of both networks in Figure 4 and plots their communities in 1979 and in 1983. Note that the proportions between communities are misleading because they only rely on papers that were in the 1979 network. The passive smoking community was the largest in 1983, but it is one of the smaller communities in Figure 5. The figure demonstrates how the passive smoking community presented a new logic that reshuffled citations and resulting communities. It also demonstrates how passive smoking united the literature in that approximately half of the articles in that community came from the safer cigarette camp, whereas the other half came 
Community in 1979

Community in 1983

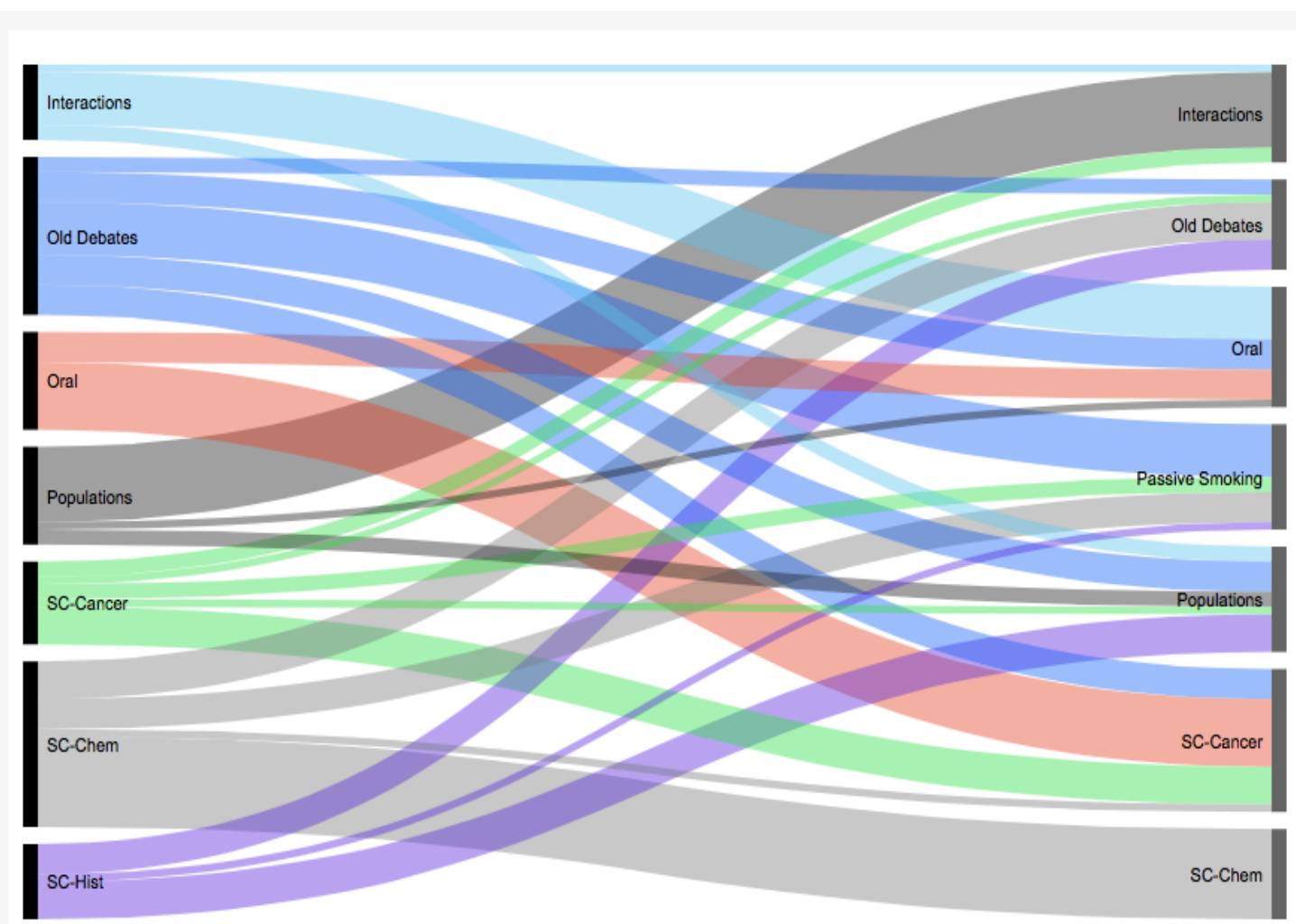

Figure 5: Community shifts in 1979-1985. One hundred papers that are present in both networks from Figure 4 for 1979 and 1983 are plotted by their community in 1979 (left-hand side) and their community in 1983 (right-hand side).

from the "old debates" community. Passive smoking was the new debate that emerged from the pursuit of a safer cigarette.

\section{Conclusions}

The history of smoking hazards research is usually told twice, about two disconnected affairs: carcinogenicity in the late 1950s and 1960s and passive smoking in the 1980s. Such accounts subscribe to a political approach that suspects the motives of any industry-funded study. Because of such accounts, the case has become a cautionary tale, which is why it is important for sociologists. There are good reasons to adopt a political approach regarding the tobacco industry, but this approach has its blind spots. Given the centrality of politics and interests in previous analyses of the case, this article accentuated the scientific history and adopted a symmet- 
rical method that asks what exactly scientists were studying and what were they debating without assuming it from their funding sources.

Harm reduction research in the 1970s is fairly absent from the secondary writing on the case, at least in comparison to the two main debates over carcinogenicity and ETS. When it is mentioned, it is retrospectively described as yet another industry manipulation (Davis 2007:171; Kluger 1996:428) or implied as such (Brandt 2007; Fields and Chapman 2003; Parascandola 2005a, 2005b, 2011). However, the scientific literature's dynamic tells a more complicated story. The harm reduction campaign descended from the experimental cancer production camp, which led the proof of tobacco's carcinogenicity. Furthermore, the passive smoking campaign was the descendent of the harm reduction effort. Alerted by the quantitative analysis to specific periods and researchers, qualitative reading completed this story: harm reduction was appealing to scholars engaged in experimental cancer production in the previous decade and to public health leaders (Fairchild and Colgrove 2004). These scholars, led by Wynder, initiated the collaboration with the industry, whose position was Janus-faced. On one hand, the industry was happy to have the brightest minds in the field working to develop a product they approved as harmless (Kluger 1996:423). On the other hand, leading this project entailed admitting that existing cigarettes were harmful. Thus the industry's response was "wary and uncertain" (Kluger 1996;426), not in any way leading and manipulating the TWG.

The novel association highlighted in this article reveals one more unanticipated reason for the industry to fear the harm reduction collaboration: the study of passive smoking hazards that emerged from the harm reduction literature. The two projects are linked structurally (see Figures 4 and 5) and through personal connections (of Hirayama and Wynder). Genealogically, the emergence of the secondhand smoking agenda from the side-stream smoke finding of the TWG was acknowledged by citations.

Examining the science of smoking hazards without prejudice enables the coherent weaving of a single story. The carcinogenicity struggles of the 1960s required the laboratory studies camp, which was crucial in obtaining a scientific consensus against the industry. After a consensus was obtained, in the 1970s, this camp sought harm reduction-in collaboration with the industry. That search was futile, but it did provide the conditions for the possibility to think about secondhand smoking, which reunited the literature in the 1980s.

Even in this iconic case of industry manipulation, we can witness a multiplicity of roles, positions, and strategies. A simple "good science versus bad industry" explanation leads commentators to doubt the integrity and motives of Ernst Wynder. However, Wynder was a generalist who confronted the industry in the 1960s and a specialist who worked with it in the 1970s. At the same time, he was shifting from Latour's (1987) portrayal of the laboratory boss to Shapin's (2008) portrayal of the research director (see Kuller 2006[10]). Perhaps, as Shapin shows for specific knowledge-saturated industries, the two are not that distant. Rather than a simple industry stunt, the TWG demonstrates Evans's (2010) conclusion that industry science is more speculative and thus more likely to innovate. However, unlike Evans's case, the innovation in this case works against the industry's interests. Tobacco scholars mobilized the industry for the goal of harm reduction-a goal in 
direct opposition to the industry's stated policy but still within the realm of the industry's interests. Although the safer cigarette was never found, the search for it brought forth the concept of passive smoking, which had an immense effect on current perceptions of smoking (Brandt 1990; Bayer and Stuber 2006). This is how science is robust: neither Wynder nor the industry scientists at the TWG anticipated, believed in, or had interest in ETS. In fact, Wynder was very late to join the ETS bandwagon (Hecht 2006). However, the community of scholars learned of this possibility, and someone else-Hirayama and, coincidently, also Trichopoulospursued this avenue. We do not know if they did so to extend knowledge, improve health, or obtain tenure. We do know that the innovative framing of the question occurred in the industry-built lab in pursuit of an agenda tailored for the industry (i.e., harm reduction). The funding and opportunities that come with industry collaboration worked in ways that were unexpected by the industry and by analysts of the "Social," who view industry funding as incriminating evidence.

There may be a bigger lesson from this story. Each generation of tobacco hazard scientists addressed different questions, but the methods, theories, and networks of the previous generation determined these questions. This story was never told in this way before because analysts had a more burning story to tell-about greed and deceit. This is the biggest problem with the "sociology of error." In other words, demarcating the "Social" (i.e., greed and deceit) and purifying "Science" from it would likely fail (Latour 2005). In the current case, interpretation-minimizing sociology (as opposed to politically laden sociology) traces where society (as opposed to society) lies: in the actor's (i.e., Wynder's) strategic network formation, first against the industry and then, with it, in the translation of conflicting interests into common goals and in the details of tiny experiments that bring about innovative research questions. Politics and society may be in every test tube, but the social scientist is never exempt from locating them anew.

\section{Notes}

1 Many interpret the Latourian move from Bloor's symmetry to the principle of "generalized symmetry" as extending Bloor's principle about true and false explanations for human and nonhuman actors. Yet this approach also indicates a simultaneous move from the Bloorian solution of explaining everything with social factors into explaining everything with the same explanation without predetermining its "mix" of social or natural factors. This particular mix is what needs to be explained anew for every problem (see Latour 1993).

2 For an elaborated discussion of a quantitative generalized symmetry for the analysis of scientific texts, see the debate in Shwed and Bearman $(2010,2012)$ and Bruggeman, Traag, and Uitermark (2012).

3 One could think of modularity as a "fit" metric for the suggested "model" of communities.

4 The low mean degree values in some of the temporal slices (see Table 1) may raise concerns about the utility of modularity for such networks. However, as elaborated later, the main leverage of this analysis is in the primary division of the network, for which the resolution limit is irrelevant. 
5 Note that whereas Figure 1 presents scaled modularity, significant divisions are determined by raw modularity - before the modularity score is divided by logged network size. Thus a contribution of 0.01 to raw modularity is indeed small.

6 For example, six types of methylchrysenes (Hoffmann, Bondinel, and Wynder 1974).

7 The Web of Science indexes 58 articles authored by Hirayama in this period, but only a small fraction of these relates to smoking, and in these, he was not the first author.

\section{References}

Abraham, John and Rachel Ballinger. 2012. “The Neoliberal Regulatory State, Industry Interests, and the Ideological Penetration of Scientific Knowledge Deconstructing the Redefinition of Carcinogens in Pharmaceuticals." Science, Technology, and Human Values 37(5):443-77. http://dx.doi.org/10.1177/0162243911424914.

Asdal, Kristin. 2012. "Context in Action - and the future of the past in STS." Science, Technology and Human Values. 37(4):379-403. http://dx . doi .org/10.1177/0162243912438271.

Barnes, Deborah E. and Lisa A. Bero. 1998. "Why Review Articles on the Health Effects of Passive Smoking Reach Different Conclusions." JAMA 279(19):1566-70. http://dx. doi . org/10.1001/jama.279.19.1566.

Bayer, Ronald and James Colgrove. 2002. "Science, Politics, and Ideology in the Campaign against Environmental Tobacco Smoke." American Journal of Public Health 92(6):949-54. http://dx.doi.org/10.2105/AJPH.92.6.949.

Bayer, Ronald and Jennifer Stuber. 2006. "Tobacco Control, Stigma, and Public Health: Rethinking the Relations." American Journal of Public Health 96(1):47-50. http://dx. doi . org/10.2105/AJPH. 2005.071886.

Bloor, David. 1976. Knowledge and Social Imagery. London: Routledge and Kegan Paul.

Brandt, Allan M. 1990. “The Cigarette, Risk, and American Culture.” Daedalus 119(4):155-76.

Brandt, Allan M. 2007. The Cigarette Century. New York: Basic Books.

Brown, James Robert. 2000. "Privatizing the University-the New Tragedy of the Commons." Science 290(5497):1701-2. http: //dx . doi .org/10.1126/science.290.5497 .1701.

Bruggeman, J., V. A. Traag, and J. Uitermark. 2012. “Detecting Communities through Network Data." American Sociological Review 77(6):1050-63. http://dx.doi.org/10. $1177 / 0003122412463574$

Brunnemann, K. D., J. D. Adams, D. P. S. Ho, and Dietrich Hoffmann. 1977. “The Influence of Tobacco Smoke on Indoor Atmospheres. II. Volatile and Tobacco Specific Nitrosamines in Main Sidestream Smoke and Their Contribution to Indoor Pollution." Pp. 876-80 in Proceedings of the Fourth Joint Conference on Sensing of Environmental Pollutants. Washington, DC: American Chemical Society.

Brunnemann, K. D. and Dietrich Hoffmann. 1978. "Chemical Studies on Tobacco Smoke. LIX. Analysis of Volatile Nitrosamines in Tobacco Smoke and Polluted Indoor Environments." IARC Scientific Publications 19:343-56.

Brunnemann, K. D., L. Yu, and Dietrich Hoffmann. 1977. “Assessment of Carcinogenic Volatile N-Nitrosamines in Tobacco and in Mainstream and Sidestream Smoke from Cigarettes." Cancer Research 37:3218-22.

Callon, Michelle. 1986. "Some Elements of a Sociology of Translation: Domestication of the Scallops and the Fishermen of St Brieuc Bay." Power, Action, and Belief: A New Sociology of Knowledge 32:196-233. 
Charlson, R. J., R. J. Charlson, S.E. Schwartz, J.M. Hales, R. D. Cess, J.A. Coakley Jr, J.E. Hansen, D.J. Hofmann. 1992. "Climate Forcing by Anthropogenic Aerosols RID C-27292008." Science 255(5043):423-30. http://dx . doi .org/10.1126/science . 255.5043.423.

Davis, Devra Lee. 2007. The Secret History of the War on Cancer. New York: Basic Books.

Evans, James A. 2010. "Industry Induces Academic Science to Know Less about More." American Journal of Sociology 116(2):389-452. http://dx . doi . org/10 . 1086/653834.

Fairchild, A. and J. Colgrove. 2004. "Out of the Ashes: The Life, Death, and Rebirth of the 'Safer' Cigarette in the United States." American Journal of Public Health 94(2):192-204. http://dx.doi.org/10.2105/AJPH.94.2.192.

Fields, N. and S. Chapman. 2003. “Chasing Ernst L Wynder: 40 Years of Philip Morris' Efforts to Influence a Leading Scientist." Journal of Epidemiology and Community Health 57(8):571-78. http://dx.doi.org/10.1136/jech.57.8.571.

Fortunato, Santo. 2010. “Community Detection in Graphs." Physics Report 486(3):38-41.

Foucault, Michel. 1973. The Birth of the Clinic: An Archaeology of Medical Perception. New York: Tavistock.

Glantz, Stanton A., D. E. Barnes, L. Bero, P. Hanauer, and J. Slade. 1995. “Looking through a Keyhole at the Tobacco Industry-the Brown-and-Williamson Documents." JAMA 274(3):219-24. http://dx.doi.org/10.1001/jama.1995.03530030039032.

Gori, Gio B. 2000. Virtually Safe Cigarettes. Burke, VA: IOS Press.

Hecht, Stephen S. 2006. "A Biomarker of Exposure to Environmental Tobacco Smoke (ETS) and Ernst Wynder's Opinion about ETS and Lung Cancer." Preventive Medicine 43(4):25660. http://dx.doi.org/10.1016/j.ypmed.2006.07.020.

Hirayama, Takeshi. 1981. "Non-smoking Wives of Heavy Smokers Have a Higher Risk of Lung-Cancer-a Study from Japan." British Medical Journal 282(6259):183-85. http: //dx.doi.org/10.1136/bmj.282.6259.183.

Hoffmann, D., W. E. Bondinel, and E. L. Wynder. 1974. “Carcinogenicity of Methylchrysenes." Science 183(4121):215-16. http://dx.doi.org/10.1126/science.183.4121.215.

Kabat, Geoffrey C. 2008. Hyping Health Risks. New York: Columbia University Press.

Kluger, R. 1996. Ashes to Ashes: America's Hundred-Year Cigarette War, the Public Health, and the Unabashed Triumph of Philip Morris. New York: Alfred A. Knopf.

Krimsky, Sheldon. 2006. "Autonomy, Disinterest, and Entrepreneurial Science." Society 43(4):22-29. http://dx.doi.org/10.1007/BF02687531.

Kuller, Lewis H. 2006. "Ernst Wynder and Preventive Medicine." Preventive Medicine 43(4):236-37. http://dx.doi.org/10.1016/j . ypmed.2006.08.003.

Lam, Alice. 2010. “From 'Ivory Tower Traditionalists' to 'Entrepreneurial Scientists'? Academic Scientists in Fuzzy University-Industry Boundaries." Social Studies of Science 40(2):307-40. http://dx.doi.org/10.1177/0306312709349963.

Latour, Bruno. 1987. Science in Action: How to Follow Scientists and Engineers through Society. Cambridge, MA: Harvard University Press.

Latour, Bruno. 1993. We Have Never Been Modern. Harvard University Press.

Latour, Bruno. 1999. “The Historisity of Things: Where Were Microbes before Pasteur?" Pp. 145-173 in Pandora's Hope: Essays on the Reality of Science Studies. Oxford: Oxford University Press.

Latour, Bruno. 2005. Reassembling the Social. Oxford: Oxford University Press. 
Leicht, E. A. and M. E. J. Newman. 2008. "Community Structure in Directed Networks." Physical Review Letters 100(11):118703. http: //dx.doi .org/10.1103/PhysRevLett. 100. 118703.

Lenoir, T. 1979. “Quantitative Foundations for the Sociology of Science-Linking Blockmodeling with Co-citation Analysis." Social Studies of Science 9(4):455-80. http: //dx.doi.org/10.1177/030631277900900404.

Markowitz, Gerald and David Rosner. 2003. Deceit and Denial. Berkley: University of California Press.

Merton, Robert K. 1987. “Three Fragments from a Sociologist's Notebooks: Establishing the Phenomenon, Specified Ignorance, and Strategic Research Materials." Annual Review of Sociology 13: 1-29. http://dx.doi.org/10.1146/annurev . so.13.080187.000245.

Michaels, David. 2008. Doubt Is Their Product: How Industry's Assault on Science Threatens Your Health. 1st ed. New York: Oxford University Press.

Mody, C. C. M. 2006. "Corporations, Universities, and Instrumental CommunitiesCommercializing Probe Microscopy, 1981-1996." Technology and Culture 47(1):56-80. http://dx.doi.org/10.1353/tech.2006.0085.

Moody, J. 2004. "The Structure of a Social Science Collaboration Network: Disciplinary Cohesion from 1963 to 1999." American Sociological Review 69(2):213-38. http: //dx. doi. org/10.1177/000312240406900204.

Mukherjee, Siddhartha. 2010. The Emperor of All Maladies: A Biography of Cancer. New York: Scribner.

Murray, Fiona. 2010. "The Oncomouse That Roared: Hybrid Exchange Strategies as a Source of Distinction at the Boundary of Overlapping Institutions 1." American Journal of Sociology 116(2):341-88. http://dx.doi.org/10.1086/653599.

Navon, Daniel and Uri Shwed. 2012. "The Chromosome 22q11.2 Deletion: From the Unification of Biomedical Fields to a New Kind of Genetic Condition." Social Science and Medicine 75(9):1633-41. http: //dx. doi.org/10.1016/j . socscimed.2012.06.023.

Ong, Elisa K. and Stanton A. Glantz. 2000. “Tobacco Industry Efforts Subverting International Agency for Research on Cancer's Second-Hand Smoke Study." The Lancet 355(9211):125359. http://dx.doi.org/10.1016/S0140-6736(00)02098-5.

Ong, Elisa K. and Stanton A. Glantz. 2001. “Constructing 'Sound Science' and 'Good Epidemiology': Tobacco, Lawyers, and Public Relations Firms." American Journal of Public Health 91(11):1749-57. http://dx .doi .org/10.2105/AJPH.91.11.1749.

Oreskes, Naomi and Erik M. M. Conway. 2010. Merchants of Doubt: How a Handful of Scientists Obscured the Truth on Issues from Tobacco Smoke to Global Warming. 1st U.S. ed. New York: Bloomsbury Press.

Parascandola, Mark. 2005a. "Lessons from the History of Tobacco Harm Reduction: The National Cancer Institute's Smoking and Health Program and the 'Less Hazardous Cigarette."' Nicotine and Tobacco Research 7(5):779-89. http://dx.doi.org/10.1080/ 14622200500262584.

Parascandola, Mark. 2005b. “Science, Industry, and Tobacco Harm Reduction: A Case Study of Tobacco Industry Scientists' Involvement in the National Cancer Institute's Smoking and Health Program, 1964-1980." Public Health Reports 120(3):338-49.

Parascandola, Mark. 2011. "Tobacco Harm Reduction and the Evolution of Nicotine Dependence." American Journal of Public Health 101(4):632-41. http://dx.doi .org/10.2105/ AJPH. 2009.189274. 
Pickering, Andrew. 1993. "The Mangle of Practice: Agency and Emergence in the Sociology of Science." American Journal of Sociology 99(3):559-89. http://dx.doi .org/10.1086/ 230316.

Pierce, John P. 1999. “Ernst Wynder: The Father of Tobacco Control 1922-1999." Nicotine and Tobacco Research 1(4):293-294. http://dx. doi.org/10.1080/14622299050011401.

Proctor, Robert. 1995. Cancer Wars. New York: Basic Books.

Proctor, Robert and Londa Schiebinger. 2008. Agnotology. Palo Alto, CA: Stanford University Press.

Resnick, David B. 2007. The Price of Truth: How Money Affects the Norms of Science. New York: Oxford University Press. http://dx.doi.org/10.1093/acprof : oso/9780195309782. 001.0001.

Rosval, Martin and Carl T. Bergstrom. 2010. "Mapping Change in Large Networks." PLoS ONE 5(1):e8694. http://dx.doi.org/10.1371/journal . pone.0008694.

Shapin, Steven. 2008. Scientific Life: A Moral History of a Late Modern Vocation. Chicago: University of Chicago Press. http://dx.doi.org/10.7208/chicago/9780226750170. 001.0001.

Shwed, Uri and Peter S. Bearman. 2010. “The Temporal Structure of Scientific Consensus Formation." American Sociological Review 75(6):817-840. http://dx .doi .org/10.1177/ 0003122410388488.

Shwed, Uri and Peter S. Bearman. 2012. "Symmetry Is Beautiful." American Sociological Review 77(6):1064-1069. http://dx.doi.org/10.1177/0003122412463018.

Smith, K. E. 2013. "Understanding the Influence of Evidence in Public Health Policy: What Can We Learn from the 'Tobacco Wars'?," Social Policy and Administration 47(4):382-98. http://dx.doi.org/10.1111/spol.12025.

Stellman, Steven D. 2006. “Ernst Wynder: A Remembrance." Preventive Medicine 43(4):239-45. http://dx.doi.org/10.1016/j.ypmed.2006.08.007.

Trichopoulos, Dimitrios, Anna Kalandidi, Loukas Sparros, and Brian Macmahon. 1981. "Lung Cancer and Passive Smoking." International Journal of Cancer 27(1):1-4. http: //dx.doi.org/10.1002/ijc.2910270102.

U.S. Surgeon General's Advisory Committee on Smoking and Health. 1964. "Smoking and Health." Public Health Service Publication 1103. Washington, DC: U.S. Government Printing Office.

U.S. Surgeon General's National Clearinghouse for Smoking and Health. 1967. The Health Consequences of Smoking: A Public Health Service Review. Public Health Service Publication 1696. Washington, DC: U.S. Government Printing Office.

Vallas, Steven P. and Daniel L. Kleinman. 2007. "Contradiction, Convergence, and the Knowledge Economy: The Confluence of Academic and Commercial Biotechnology." Socio-Economic Review 6(2):283-311. http://dx.doi.org/10.1093/ser/mw1035.

Vilhena, Daril A., Jacob G. Foster, Martin Rosvall, Jevin D. West, James Evans, and Carl T. Bergstrom. 2014. "Finding Structural Holes: How Structure and Culture Diverge in Networks of Scholarly Communication." Sociological Science 1:221-38. http://dx. doi. org/10.15195/v1.a15.

White, H. D. 1997. “Tobacco as a Cause of Lung Cancer: Some Reflections." American Journal of Epidemiology 146(9):687-94. http://dx.doi.org/10.1093/oxfordjournals . aje.a009342.

White, H. D. 2000. "Toward Ego-Centered Citation Analysis." Pp. 475-96 in Web of Knowledge-a Festschrift in Honor of Eugene Garfield. Today Inc, Medford NJ. 
Wynder, Ernest L. and Evarts A. Graham. 1950. "Tobacco Smoking as a Possible Etiological Factor in Bronchiogenic Carcinoma." JAMA 143:329-36. http://dx . doi .org/10.1001/ jama.1950.02910390001001.

Wynder, Ernest L., Evarts A. Graham, and Adele B. Croninger. 1953. “Experimental Production of Carcinoma with Cigarette Tar." Cancer Research 13(12):855-64.

Wynder, E. L. and T. Hirayama. 1977. "Comparative Epidemiology of Cancers of the United States and Japan." Preventive Medicine 6(4):567-94. http://dx . doi .org/10 . 1016/ 0091-7435 (77) 90042-1.

Wynder, Ernest L. and Dietrich Hoffmann. 1963. "Experimental Aspects of Tobacco Carcinogenesis." Diseases of the Chest 44(4):337-44. http://dx. doi . org/10.1378/chest .44.4. 337.

Wynder, Ernest L. and Dietrich Hoffmann. 1964. "Experimental Tobacco Carcinogenesis." Advances in Cancer Research 8:249-453. http://dx.doi .org/10.1016/S0065-230X (08) 60510-2.

Acknowledgements: I thank Peter Bearman, Gil Eyal, Daniel Navon, James Evans, participants of the BGU Sociology and Anthropology research seminar, and Sociological Science's anonymous reviewers for their valuable comments. Parts of this study were enabled by the Binational Israeli American Science Foundation, grant 2010175, as well as by NSF Dissertation Improvement grant 524794 .

Uri Shwed: Department of Sociology and Anthropology, Ben Gurion University of the Negev. E-mail: shwed@bgu.ac.il. 